\title{
Importance of the surface exchange kinetics as rate limiting step in oxygen permeation through mixed-conducting oxides
}

\author{
H.J.M. Bouwmeester, H. Kruidhof and A.J. Burggraaf \\ Laboratory for Inorganic Chemistry, Materials Science and Catalysis, Department of Chemical Technology, \\ University of Twente, PO Box 217, 7500 AE Enschede, The Netherlands
}

\begin{abstract}
Attention is drawn to the possible involvement of the surface exchange kinetics in limiting the rate of oxygen permeation through mixed-conducting oxide ceramics. A theoretical approach is provided with which it is possible to distinguish between surface exchange- and bulk diffusion controlled kinetics of oxygen permeation. New results on the oxygen permeability of perovskites $\mathrm{La}_{0.8} \mathrm{Sr}_{0.2} \mathrm{CoO}_{3-\delta}$ and $\mathrm{SrCo}_{0.8} \mathrm{Fe}_{0.2} \mathrm{O}_{3-\delta}$ are presented. The importance of the exchange reaction relative to diffusion in limiting overall oxygen transport through $(\mathrm{La}, \mathrm{Sr})(\mathrm{Co}, \mathrm{Fe}) \mathrm{O}_{3-\delta}$ perovskite-type oxides is emphasized.
\end{abstract}

\section{Introduction}

Mixed ionic-electronic conductors find wide application in solid-state electrochemical devices such as solid oxide fuel cells, batteries, sensors and displays. The same materials also hold particular promise as ceramic membranes designed to separate oxygen from air, being impervious to other gaseous constituents (if fully densified). High oxygen fluxes have been measured through mixed-conducting oxides with the fluorite and perovskite structure [1]. Since the operating temperature at which the oxygen flux becomes significant is in the range where many partial oxidation reactions occur, another potential use would be the selective feeding (or extracting) of oxygen in chemical reactors. e.g., in hydrocarbon oxidation and dehydrogenation processes [2-4].

Presently intensive research is conducted on mixed-conducting perovskite oxides. Teraoka et al. [5-7] were the first to measure high permeability fluxes through perovskites $(\mathrm{La}, \mathrm{A})(\mathrm{Co}, \mathrm{B}) \mathrm{O}_{3-\delta}$ $(\mathrm{A}=\mathrm{Sr}, \mathrm{Ca}, \mathrm{Ba}, \mathrm{B}=\mathrm{Fe}, \mathrm{Co}, \mathrm{Cu}, \mathrm{Ni})$. The oxygen fluxes were found to be roughly proportional to the oxygen ion conductivity of the perovskites. Though the perovskites show predominant electronic conduction, the magnitude of the ionic conductivity can be much larger $(>100 \times)$ than that of stabilized zirconia. The highest oxygen permeation rate was found for $\mathrm{SrCo}_{0.8} \mathrm{Fe}_{0.2} \mathrm{O}_{3-\delta}$ [6]. In a previous report on perovskites $\mathrm{SrCo}_{0.8} \mathrm{~B}_{0.2} \mathrm{O}_{3-\delta}(\mathrm{B}=\mathrm{Fe}, \mathrm{Co}, \mathrm{Cu}, \mathrm{Ni})$, we showed that the oxygen permeability of these highly nonstoichiometric oxides may be drastically affected by the occurrence of order-disorder phenomena at elevated temperatures [8]. The values of our permeability data for $\mathrm{SrCO}_{0.8} \mathrm{Fe}_{0.2} \mathrm{O}_{3-\delta}$ are, however, one order of magnitude lower than those given by Teraoka et al.

One obvious method to increase the oxygen flux, or to reduce operating temperatures, seems to decrease membrane thicknesses to values in the $\mu \mathrm{m}$ range by making use of thin film techniques. A number of techniques are presently available for the preparation of thin oxidic films, e.g., sol-gel processing, gas phase deposition techniques and sputtering (ion beam and laser ablation). For sufficient mechanical rigidity these, dense and crack-free, thin films must be supported on porous substrates. It is evident that high surface exchange rates are a prerequisite to sustain the potentially high oxygen fluxes through the membranes.

In general, the chemically driven oxygen flux through a mixed-conducting oxide is modelled using Wagner's theory of oxide film growth, with the usual assumption that the gas phase boundaries equilibrate fast with the imposed gas atmospheres. In actual application the surface reaction may exert a partial control over the transport kinetics, the extent of which may vary with membrane thickness, temper- 
ature and gradient in oxygen partial pressure imposed across the membrane. In this paper, examples are provided which emphasize the importance of the surface exchange kinetics in limiting the magnitudes of chemically driven oxygen fluxes through oxide ceramics. A model is proposed with which it is possible to distinguish tentatively between surface exchange and bulk diffusion controlled kinetics.

\section{Wagner's theory}

The scheme of a membrane semipermeable to oxygen is shown in fig. 1. By applying a $P_{\mathrm{O}_{2}}$ differential, oxygen is driven through the membrane from the high $P_{\mathrm{O}_{2}}$ to the low $P_{\mathrm{O}_{2}}$ side. The oxygen flux is enabled by the simultaneous diffusion of oxygen anions and electrons, or associated lattice defects, in the mixed-conducting oxide under the driving force of a gradient in oxygen chemical potential, $\nabla \mu_{\mathrm{O}_{2}}$. Metal ion diffusion in the materials under consideration can be left out of consideration.

In actual application one is interested in the magnitude of the permeating flux as a function of the partial pressure applied to the two sides of the membrane. Wagner's theory of oxide film growth on metals provides a means by which the oxygen flux can be related to measurable electrical parameters [9],

$j_{\mathrm{O}_{2}}=\frac{-t_{\mathrm{el}} t_{\text {ion }} \sigma_{\mathrm{total}}}{4^{2} F^{2}} \nabla \mu_{\mathrm{O}_{2}}$

where $t_{\text {ion }}$ and $t_{\mathrm{el}}$ are the fractions (transference numbers) of the total conductivity, $\sigma_{\text {total }}$ $\left(=\sigma_{\mathrm{ion}}+\sigma_{\mathrm{el}}\right)$, which are provided by ionic and electronic defects, respectively, and $F$ the Faraday con-

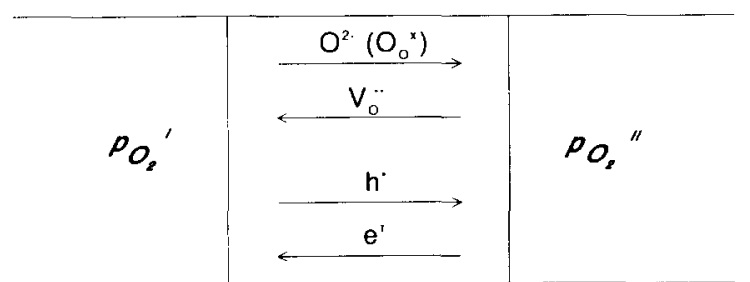

$$
1 / 2 \mathrm{O}_{2}+\mathrm{V}_{\mathrm{O}}{ }^{\prime} \rightarrow \mathrm{O}_{0}{ }^{\mathrm{x}}+2 \mathrm{~h}^{\cdot} \quad \mathrm{O}_{0}{ }^{x}+2 \mathrm{~h}^{\cdot} \rightarrow 1 / 2 \mathrm{O}_{2}+\mathrm{V}_{\mathrm{O}} \cdot
$$

Fig. 1. Representation of relevant fluxes through a ceramic membrane upon applying a $P_{\mathrm{O}_{2}}$ differential, $P_{\mathrm{O}_{2}}^{\prime}>P_{\mathrm{O}_{2}}^{\prime \prime}$. stant. In deriving eq. (1), it is assumed that local thermodynamic equilibrium for internal defect reactions is not disturbed by the transport. Wagner further assumed that there is no divergence in the ionic and electronic currents, which compensate each other such that there is no net charge transport. Evaluation of $j_{\mathrm{O}_{2}}$ from eq. (1) requires that data exist for the partial conductivities $\sigma_{\mathrm{el}}$ and $\sigma_{\mathrm{ion}}$ as a function of oxygen partial pressure. The exact relationship depends on the specific defect chemistry of the oxide being considered [10]. In a simplified form, eq. (1) may be rewritten as,

$j_{\mathrm{O}_{2}}=\frac{\overline{-t_{\mathrm{el}} t_{\text {ion }} \sigma_{\text {total }}}}{4^{2} F^{2}} \frac{\Delta \mu_{\mathrm{O}_{2}}}{L}$,

where the factor $\overline{t_{\mathrm{el}} t_{\text {ion }} \sigma_{\text {total }}}$ is the average value of the product across the thickness, $L$, of the membrane.

\section{Importance of the surface exchange kinetics}

Wagner's equation (eq. (1)) is valid if one assumes that bulk oxide properties dominate the transport. It involves that the surface reactions proceeding at the gas phase boundaries have reached a quasiequilibrium condition relative to diffusion through the membrane. In actual application the surface reaction may exert a partial control over the rate of oxygen permeation. The gradient in oxygen chemical potential will be consumed partly by the surface exchange kinetics at the expense of the gradient across the oxide bulk. Oxygen permeation will be controlled by diffusion if the membrane is made sufficiently thick. A mixed type of control is encountered upon decreasing thickness. Ultimately the surface reactions will become rate determining for very thin membranes.

The importance of the surface exchange kinetics in determining oxygen fluxes through oxide ceramics has been recognized by a number of authors. Dou et al. [11] observed that the rate of oxygen permeation through calcia-stabilized zirconia (CSZ) is limited partly by diffusion (of electron holes) within the solid and partly by the surface reactions. A similar observation has been made in our laboratory studying the oxygen permeability of dense ceramics of bismuth oxide stabilized with $25 \mathrm{~mol} \%$ erbia (BE25), even though this electrolyte shows large intrinsic activity 
in oxygen exchange [11]. In contrast to $\mathrm{ZrO}_{2}$-based electrolytes, electrode materials as $\mathrm{Pt}$ and $\mathrm{Ag}$ do not show any influence on the exchange kinetics of $\mathrm{Bi}_{2} \mathrm{O}_{3}-$ based electrolytes [13-15].

The influence of the surface on the (re-)equilibration kinetics of nonstoichiometric oxides has been investigated by Nowotny and Wagner [16], emphasizing the possible role of segregation of lattice components towards the surface. A large number of kinetic studies are considered in which the data from relaxation experiments appear to exhibit mixed control, i.e., the overall kinetics is determined by both surface reactions and bulk diffusion. The authors propose a model in which the transport of lattice defects towards the surface, and vice versa, is affected by the electrical barrier generated across the junction between the crystalline bulk and a quasi-isolated segregated surface layer (see also refs. [17] and [18]).

Using data of combined ${ }^{18} \mathrm{O}-{ }^{16} \mathrm{O}$ exchange and secondary ion mass spectroscopy (SIMS) Carter, Steele and co-workers [19-21] arrived at the conclusion that the potentially high oxygen fluxes that would be allowed through the cobaltite perovskites seem limited by the surface exchange. Evidence comes from the comparatively small values observed for the perovskites of the ratio $h=k / D^{*}$, where $k$ is the surface exchange coefficient and $D^{*}$ the tracer diffusion coefficient. Both quantities are obtained simultaneously from a single experiment by fitting ${ }^{18} \mathrm{O}$ / $\left({ }^{16} \mathrm{O}+{ }^{18} \mathrm{O}\right)$ depth profiles to the appropriate diffusion equation after isotopic exchange at high temperature for a selected time. The smaller the $h$ value, the more the isotopic exchange process is inhibited by the surface exchange kinetics relative to diffusion within the solid, and vice versa. As shown in the next section, under the specific assumptions made, $h$ represents the reciprocal membrane thickness at which oxygen permeation is equally determined by bulk diffusion and surface exchange. The procedure followed is basically similar to that described by Schmalzried [22] in an analysis of the deviation from the theoretical EMF of galvanic cells under open circuit condition due to the existence of a nonvanishing semipermeability flux through the oxide electrolyte.

\section{Kinetics of oxygen permeation under a partial rate control by the surface exchange reaction}

To extend Wagner's theory to cases of partial rate control by a surface reaction it is expedient to divide the ceramic membrane into three regions: a central bulk (Wagner) zone and adjacent interfacial zones, emphasizing the importance of both solid state diffusion and surface oxygen exchange to the extent of oxygen permeation. The total driving force, $\Delta \mu_{\mathrm{O}_{2}}$, is distributed between the various zones, as schematically depicted in fig. 2 , such that the rate controlling process receives the greater proportion. In the steadystate approximation, the oxygen flux is given by

$$
\begin{aligned}
J_{\mathrm{O}_{2}} & =-j_{\mathrm{ex}}^{0} \frac{\Delta \mu_{\mathrm{O}_{2}}^{\prime}}{R T}=\overline{-\bar{t}_{\mathrm{el}} t_{\text {ion }} \sigma_{\text {total }}} \frac{\Delta \mu_{\mathrm{O}_{2}}^{\text {bulk }}}{4^{2} F^{2}} \\
& =-j_{\mathrm{ex}}^{0 \prime \prime} \frac{\Delta \mu_{\mathrm{O}_{2}}^{\prime \prime}}{R T}
\end{aligned}
$$

where $\Delta \mu_{\mathrm{O}_{2}}^{\text {bulk }}, \Delta \mu_{\mathrm{O}_{2}}^{\prime}$ and $\Delta \mu_{\mathrm{O}_{2}}^{\prime \prime}$ designate the respective driving forces across the bulk and interfacial zones. Single and double primes refer to the high and low pressure side, respectively. The Onsager equation that has been adopted for the surface reaction is valid only at conditions near to equilibrium and disregards non-linear effects that may occur at high oxygen potential gradients. The kinetic parameter, $j_{\mathrm{ex}}^{0}$, represents the balanced exchange rate in the absence of oxygen potential gradients. Its value can be determined directly using ${ }^{18} \mathrm{O}-{ }^{16} \mathrm{O}$ isotopic ex-

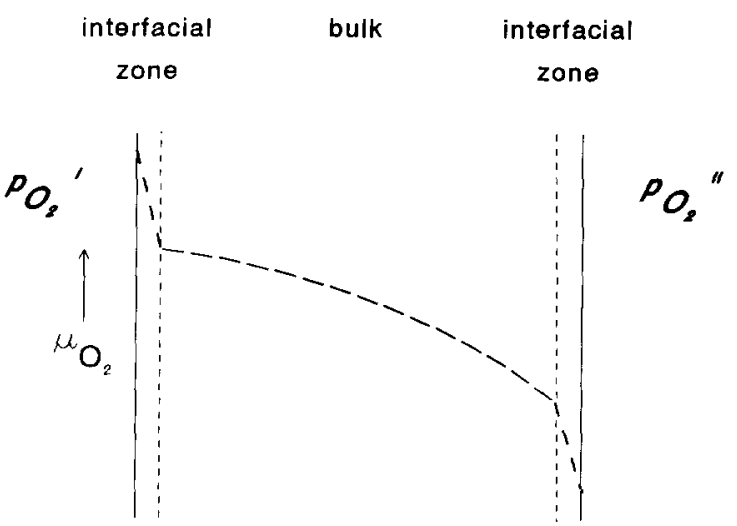

Fig. 2. Schematic representation of the gradient in oxygen chemical potential, $\mu_{\mathrm{O}_{2}}$, at various zones during steady state oxygen permeation. 
change techniques and generally is found to be a function of the oxygen partial pressure of the type, $j_{\mathrm{ex}}^{0} \propto P_{\mathrm{O}_{2}}^{m}$ [23]. Since we are restricted in our derivation to cases in which only small $P_{\mathrm{O}_{2}}$-gradients appear across the membrane, it follows that $j_{\mathrm{ex}}^{0 \prime} \approx j_{\mathrm{ex}}^{0 \prime \prime}$. That is, at steady state near to equilibrium the exchange rates at opposite interfaces are of similar order of magnitude, if the two sides of the membrane are not exposed to different gas ambients. In general, the exchange rate will be different in, for instance, $\mathrm{O}_{2}-\mathrm{N}_{2}, \mathrm{CO}-\mathrm{CO}_{2}, \mathrm{H}_{2}-\mathrm{H}_{2} \mathrm{O}$ atmospheres, even at the same oxygen partial pressure. The surface oxygen exchange rate, $j_{\mathrm{ex}}^{0}\left(\mathrm{~mol} \mathrm{O}_{2} \mathrm{~cm}^{-2} \mathrm{~s}^{-1}\right)$, is related to the surface exchange coefficient, $k\left(\mathrm{~cm} \mathrm{~s}^{-1}\right)$, which expresses the exchange flux ( $\mathrm{mol} \mathrm{O} \mathrm{cm}^{-2} \mathrm{~s}^{-1}$ ) normalized to the molar concentration, $c_{i}$, of oxygen anions at equilibrium,

$j_{\mathrm{ex}}^{0}=\frac{1}{2} k c_{i}$.

As the condition corresponding to mixed control, we adopt,

$\Delta \mu_{\mathrm{O}_{2}}^{\text {bulk }}=\Delta \mu_{\mathrm{O}_{2}}^{\prime}+\Delta \mu_{\mathrm{O}_{2}}^{\prime \prime}$.

That is, the total driving force is equally used for diffusion and for the surface exchange. Note that since $j_{e x}^{0 \prime} \approx j_{e x}^{0 \prime \prime}$ also $\Delta \mu_{\mathrm{O}_{2}}^{\prime} \approx \Delta \mu_{\mathrm{O}_{2}}^{\prime \prime}$ is valid so that the prime notation is no longer necessary. From eq. (3), one finds that the condition expressed by eq. (5) is satisfied at a characteristic thickness, $L_{\mathrm{c}}$,

$L_{\mathrm{c}}=\frac{R T}{8 F^{2}} \frac{t_{\mathrm{el}} t_{\mathrm{ion}} \sigma_{\mathrm{total}}}{j_{\mathrm{ex}}^{0}}$,

where the averaging of $t_{\mathrm{el}} t_{\text {ion }} \sigma_{\text {total }}$ has been omitted since only small $P_{\mathrm{O}_{2}}$ gradients are assumed.

In perovskite-type oxides such as $(\mathrm{La}, \mathrm{Sr})(\mathrm{Co}, \mathrm{Fe}) \mathrm{O}_{3-\delta}$ the ionic conductivity is much smaller than the electronic conductivity. Assuming the ionic conduction to be purely anionic, the NernstEinstein relationship is given by,

$\sigma_{\text {ion }}=\frac{c_{i} D_{i} z_{i}^{2} F^{2}}{R T}$

in which $D_{i}$ is the self-diffusion coefficient of oxygen anions with valence charge $z_{i}(=-2)$. By combining eqs. (4), (6), (7) and putting $t_{\mathrm{el}}=1$, one arrives at

$L_{\mathrm{c}}=\frac{D_{i}}{k}=\frac{D^{*}}{k}=\frac{1}{h}$.
In the second part of eq. (8) the fact has been used that, if correlation effects can be neglected, the tracer diffusion coefficient, $D^{*}$, is identical to the self-diffusion coefficient, $D_{i}$. It should be reemphasized that the use of eqs. (6) and (8) to calculate $L_{c}$ is valid only for small $P_{\mathrm{O}_{2}}$ gradients across the ceramic membrane, while in the derivation of eq. (8) the additional assumption is made that the oxide shows predominant electronic conduction.

\section{Evaluation of $L_{\mathrm{c}}$ for selected oxides}

Data of oxygen permeability allow direct determination of the conductivity parameters and the surface exchange rate provided that the diffusion mechanism and that of the surface reaction are known. Under conditions of mixed control, the experimental order with respect to oxygen and the activation energy will have different contributing factors. The rate controlling process may be altered by changing either the temperature, membrane thickness or the imposed gradient in oxygen partial pressure.

In spite of the information that can be extracted from experiment, complete data sets on the oxygen permeability are scarce. Thus far detailed measurements have only been performed on oxide electrolytes CSZ [10] and BE25 [11]. In the treatment below, examples are provided illustrating that the characteristic thickness, $L_{\mathrm{c}}$, is a convenient measure to distinguish between surface exchange and diffusion controlled kinetics of oxygen permeation. It should, however, be emphasized that the value of $L_{\mathrm{c}}$, below which the oxygen flux will be predominantly controlled by the surface exchange kinetics, may be specific to the particular sample under investigation. For example, a different morphology and microstructure of the membrane surface could produce a different value for the exchange rate, $j_{\mathrm{ex}}^{0}$, and, hence. for $L_{\mathrm{c}}$.

\subsection{BE25 and CSZ}

Oxygen permeation through relatively thick membranes of $\mathrm{BE} 25$ ceramics at $10 \mathrm{~Pa} \leq P_{\mathrm{O}_{2}} \leq 100 \mathrm{kPa}$ and $610 \leq T \leq 810^{\circ} \mathrm{C}$ appears to be governed by the partial electron-hole conductivity, having an order 
of $\frac{1}{4}$ with respect to oxygen [11]. The experimental order increases gradually with decreasing specimen thickness (or temperature) due to the change from diffusion-control to surface-control. From the rate equations used in modelling the experimental data, it follows that

$\sigma_{\mathrm{el}} \propto P_{\mathrm{O}_{2}}^{1 / 4} ; j_{\mathrm{ex}}^{0} \propto P_{\mathrm{O}_{2}}^{5 / 8}$.

The surface oxygen exchange rate thus obtained showed excellent agreement with the value measured directly by experiment using gas phase ${ }^{18} \mathrm{O}-{ }^{16} \mathrm{O}$ isotopic exchange [12].

Calculations were made of the characteristic thickness, $L_{\mathrm{c}}$, for BE25 using data obtained from permeability measurements. As shown in table $1, L_{\mathrm{c}}$ increases with decreasing partial pressure, in agreement with eqs. (6) and (9). The experimental thickness at which the oxygen flux is half of that expected if diffusion would act exclusively, imposing opposite sides of disc specimens to pure oxygen and helium $\left(P_{\mathrm{O}_{2}} \approx 10 \mathrm{~Pa}\right)$ at 650 and $800^{\circ} \mathrm{C}$, was estimated to be $0.16 \mathrm{~cm}$ and $0.09 \mathrm{~cm}$, respectively. Note that these values are intermediate between the calculated $L_{\mathrm{c}}$ values given in table 1 .

Similar calculations were made for CSZ, using the proportionalities,

$\sigma_{\mathrm{el}} \propto P_{\mathrm{O}_{2}}^{1 / 4}, \quad j_{\mathrm{ex}}^{0} \propto P_{\mathrm{O}_{2}}^{1 / 2}$,

which are valid in the range of temperatures and partial pressures examined in the experiments performed by Dou et al. [11]. In analogy with BE25, the $L_{\mathrm{c}}$ values increase with decreasing oxygen partial pressure (see table 1). Dou et al. derived a characteristic thickness for $\mathrm{CSZ}$ at $1230^{\circ} \mathrm{C}$ of $0.027 \mathrm{~cm}$. The latter value was calculated from a kinetic parameter (ratio $\beta / \alpha$ in eq. (7) of ref. [11]) used in modelling the experimental data of oxygen permeability. It is seen from table 1 that their value corresponds to the standard state $P_{\mathrm{O}_{2}}=100 \mathrm{kPa}$.

\section{2. $B T 40$}

Extrinsic electronic conduction in ionically conducting oxides can be obtained by dissolution of multivalent cations in the oxide lattice [23]. An example is titania dissolved in yttria stabilized zirconia. In our laboratory we have investigated $\mathrm{Bi}_{2} \mathrm{O}_{3}$ substituted with $40 \mathrm{~mol} \% \mathrm{~Tb}_{2} \mathrm{O}_{3.5}$ (BT40). The results from conductivity measurements and gas phase ${ }^{18} \mathrm{O}-{ }^{16} \mathrm{O}$ exchange, as summarized elsewhere $[25,26]$, show that the phase is a mixed conductor with an appreciable electronic conductivity.

Recent oxygen permeability measurements revealed that, under identical experimental conditions (see section 5.1), the observed oxygen flux through disc specimens of BT 40 with a thickness varying between $0.07-0.17 \mathrm{~cm}$ is comparable in magnitude to that observed for BE25. The experimental order with respect to oxygen was found to be close to $1 / 2$ [27].

The characteristic thickness, $L_{\mathrm{c}}$, for BT40 has been calculated using data of $\sigma_{\mathrm{el}}, t_{\mathrm{ion}}$ and $j_{\mathrm{ex}}^{0}$ obtained from the above study $[25,26]$. From the large values found

Table 1

Ionic transference number, $t_{\mathrm{ion}}$, electronic conductivity, $\sigma_{\mathrm{e}}$, surface oxygen exchange rate, $j_{\mathrm{ex}}^{0}$, and characteristic thickness, $L_{\mathrm{c}}$, for CSZ, BE25 and BT40 (see text).

\begin{tabular}{|c|c|c|c|c|c|c|c|}
\hline Material & $\begin{array}{l}T \\
\left({ }^{\circ} \mathrm{C}\right)\end{array}$ & $\begin{array}{l}P_{\mathrm{O}_{2}} \\
(\mathrm{~Pa})\end{array}$ & $t_{\text {ion }}$ & $\begin{array}{l}\sigma_{\mathrm{el}} \\
\left(\mathrm{S} \mathrm{cm}^{-1}\right)\end{array}$ & $\begin{array}{l}j_{\mathrm{ex}}^{0} \\
\left(\mathrm{~mol} \mathrm{~cm}{ }^{-2} \mathrm{~s}^{-1}\right)\end{array}$ & $\begin{array}{l}L_{\mathrm{c}}^{\mathrm{a})} \\
(\mathrm{cm})\end{array}$ & Refs. \\
\hline $\operatorname{CsZ}$ & $\begin{array}{l}1230 \\
1230\end{array}$ & $\begin{array}{l}1 \times 10^{5} \\
1 \times 10^{1}\end{array}$ & $\begin{array}{l}1 \\
1\end{array}$ & $\begin{array}{l}9.0 \times 10^{-3} \\
9.0 \times 10^{-4}\end{array}$ & $\begin{array}{l}5.7 \times 10^{-8} \\
5.7 \times 10^{-10}\end{array}$ & $\begin{array}{l}2.7 \times 10^{-2} \\
2.7 \times 10^{-1}\end{array}$ & [11] \\
\hline \multirow[t]{2}{*}{ BE25 } & $\begin{array}{l}650 \\
650\end{array}$ & $\begin{array}{l}1 \times 10^{5} \\
1 \times 10^{1}\end{array}$ & $\begin{array}{l}1 \\
1\end{array}$ & $\begin{array}{l}2.1 \times 10^{-3} \\
2.1 \times 10^{-4}\end{array}$ & $\begin{array}{l}5.2 \times 10^{-9} \\
1.6 \times 10^{-11}\end{array}$ & $\begin{array}{l}4.2 \times 10^{-2} \\
1.3\end{array}$ & {$[12]$} \\
\hline & $\begin{array}{l}800 \\
800\end{array}$ & $\begin{array}{l}1 \times 10^{5} \\
1 \times 10^{1}\end{array}$ & $\begin{array}{l}1 \\
1\end{array}$ & $\begin{array}{l}1.1 \times 10^{-2} \\
1.1 \times 10^{-3}\end{array}$ & $\begin{array}{l}6.2 \times 10^{-8} \\
1.9 \times 10^{-10}\end{array}$ & $\begin{array}{l}2.1 \times 10^{-2} \\
6.8 \times 10^{-1}\end{array}$ & [12] \\
\hline \multirow[t]{2}{*}{ BT 40} & 650 & $2.1 \times 10^{4}$ & 0.74 & $6.2 \times 10^{-1}$ & $1.4 \times 10^{-8}$ & 3.4 & [25] \\
\hline & 800 & $2.1 \times 10^{4}$ & 0.85 & 2.2 & $\left.9.3 \times 10^{-8 b}\right)$ & 2.5 & {$[25]$} \\
\hline
\end{tabular}

a) Calculated from eq. (6). b) Extrapolated value. 
for $L_{\mathrm{c}}$, listed in table 1 , it can be inferred that oxygen permeation through BT40 in the studied thickness range, and at the temperatures and $P_{\mathrm{O}_{2}}$ gradients covered by experiment, is a surface controlled process.

\subsection{Perovskite-type oxides}

Data of oxygen tracer-diffusion coefficient, $D^{*}$, and surface exchange coefficient, $k$, for perovskite-type oxides from ${ }^{18} \mathrm{O}-{ }^{16} \mathrm{O}$ isotope exchange techniques obtained by various authors are compiled in table 2 . High $D^{*}$ and $k$ values are reported for the ferrites and cobaltites, which anions are assumed to move via a vacancy diffusion mechanism $[28,29]$. These values may therefore be a function of the oxygen nonstoichiometry. The comparatively low value of $D^{*}$ observed for $\mathrm{La}_{0.5} \mathrm{Sr}_{0.5} \mathrm{MnO}_{3-\delta}$ is attributed to the small negative departure of oxygen stoichiometry exhibited at the temperature and oxygen pressure examined [20].

There is a slight tendency for the $L_{\mathrm{c}}$ values, listed in table 2, to increase with increasing temperature and dopant concentration. Leaving $\mathrm{La}_{0.5} \mathrm{Sr}_{0.5} \mathrm{MnO}_{3-\delta}$ and the results obtained for the single crystal specimens out of consideration, the $L_{\mathrm{c}}$ values range between $20 \mu \mathrm{m}-3000 \mu \mathrm{m}\left(\right.$ at $\left.900^{\circ} \mathrm{C}\right)$, the highest value being found for $\mathrm{La}_{0.6} \mathrm{Sr}_{0.4} \mathrm{Co}_{0.4} \mathrm{Ni}_{0.6} \mathrm{O}_{3-\delta}$. The derived results clearly emphasize the importance of the exchange reaction rate, relative to diffusion, in lim-

Table 2

Tracer-diffusion coefficient, $D^{*}$, surface exchange coefficient, $k$, and characteristic thickness, $L_{c}$, for selected perovskite-type oxides.

\begin{tabular}{|c|c|c|c|c|c|c|}
\hline Material & $\begin{array}{l}T \\
\left({ }^{\circ} \mathrm{C}\right)\end{array}$ & $\begin{array}{l}P_{\mathrm{O}_{2}} \\
(\mathrm{kPa})\end{array}$ & $\begin{array}{l}D^{*} \\
\left(\mathrm{~cm}^{2} \mathrm{~s}^{-1}\right)\end{array}$ & $\begin{array}{l}k^{\mathrm{b})} \\
\left(\mathrm{cm} \mathrm{s}^{-1}\right)\end{array}$ & $\begin{array}{l}L_{\mathrm{c}}^{\mathrm{a})} \\
(\mathrm{cm})\end{array}$ & Refs. \\
\hline $\mathrm{La}_{0.5} \mathrm{Sr}_{0.5} \mathrm{MnO}_{3-\delta}$ & $\begin{array}{l}700 \\
800 \\
900\end{array}$ & 70 & $\begin{array}{l}2 \times 10^{-15} \\
8 \times 10^{-14} \\
3 \times 10^{-12}\end{array}$ & $\begin{array}{l}1 \times 10^{-8} \\
1 \times 10^{-7} \\
9 \times 10^{-8}\end{array}$ & $\begin{array}{l}2 \times 10^{-7} \\
8 \times 10^{-7} \\
3 \times 10^{-5}\end{array}$ & {$[20]$} \\
\hline $\mathrm{La}_{0.8} \mathrm{Sr}_{0.2} \mathrm{CoO}_{3-\delta}$ & $\begin{array}{l}700 \\
800 \\
900\end{array}$ & 70 & $\begin{array}{l}1 \times 10^{-8} \\
2 \times 10^{-8} \\
4 \times 10^{-8}\end{array}$ & $\begin{array}{l}3 \times 10^{-6} \\
5 \times 10^{-6} \\
2 \times 10^{-5}\end{array}$ & $\begin{array}{l}3 \times 10^{-3} \\
4 \times 10^{-3} \\
2 \times 10^{-3}\end{array}$ & {$[20]$} \\
\hline $\mathrm{La}_{0.6} \mathrm{Ca}_{0.4} \mathrm{Co}_{0.8} \mathrm{Fe}_{0.2} \mathrm{O}_{3-\delta}$ & $\begin{array}{l}700 \\
800 \\
900\end{array}$ & 70 & $\begin{array}{l}2 \times 10^{-8} \\
1 \times 10^{-7} \\
3 \times 10^{-7}\end{array}$ & $\begin{array}{l}4 \times 10^{-6} \\
2 \times 10^{-5} \\
4 \times 10^{-5}\end{array}$ & $\begin{array}{l}5 \times 10^{-3} \\
5 \times 10^{-3} \\
7 \times 10^{-3}\end{array}$ & {$[20]$} \\
\hline $\mathrm{La}_{0.6} \mathrm{Sr}_{0.4} \mathrm{Co}_{0.8} \mathrm{Ni}_{0.2} \mathrm{O}_{3-\delta}$ & $\begin{array}{l}700 \\
800 \\
900\end{array}$ & 70 & $\begin{array}{l}3 \times 10^{-8} \\
1 \times 10^{-7} \\
4 \times 10^{-7}\end{array}$ & $\begin{array}{l}2 \times 10^{-6} \\
2 \times 10^{-6} \\
2 \times 10^{-6}\end{array}$ & $\begin{array}{l}2 \times 10^{-2} \\
5 \times 10^{-2} \\
2 \times 10^{-1}\end{array}$ & {$[21]$} \\
\hline $\mathrm{La}_{0.6} \mathrm{Sr}_{0.4} \mathrm{Co}_{0.6} \mathrm{Ni}_{0.4} \mathrm{O}_{3-\delta}{ }^{\mathrm{c})}$ & $\begin{array}{l}700 \\
800 \\
900\end{array}$ & 70 & $\begin{array}{l}2 \times 10^{-9} \\
6 \times 10^{-8} \\
3 \times 10^{-7}\end{array}$ & $\begin{array}{l}7 \times 10^{-7} \\
3 \times 10^{-6} \\
3 \times 10^{-6}\end{array}$ & $\begin{array}{l}3 \times 10^{-3} \\
2 \times 10^{-2} \\
1 \times 10^{-1}\end{array}$ & [21] \\
\hline $\mathrm{La}_{0.6} \mathrm{Sr}_{0.4} \mathrm{Co}_{0.4} \mathrm{Ni}_{0.6} \mathrm{O}_{3-\delta}$ & $\begin{array}{l}700 \\
800 \\
900\end{array}$ & 70 & $\begin{array}{l}1 \times 10^{-8} \\
7 \times 10^{-8} \\
6 \times 10^{-7}\end{array}$ & $\begin{array}{l}3 \times 10^{-7} \\
2 \times 10^{-6} \\
2 \times 10^{-6}\end{array}$ & $\begin{array}{l}3 \times 10^{-2} \\
3 \times 10^{-2} \\
3 \times 10^{-1}\end{array}$ & [21] \\
\hline $\begin{array}{l}\mathrm{LaCoO}_{3-\delta} \\
\text { ( single crystal) }\end{array}$ & $\begin{array}{l}700 \\
800 \\
900\end{array}$ & 4.5 & $\begin{array}{l}9 \times 10^{-13} \\
2 \times 10^{-11} \\
6 \times 10^{-10}\end{array}$ & $\begin{array}{l}1 \times 10^{-9} \\
3 \times 10^{-7} \\
1 \times 10^{-6}\end{array}$ & $\begin{array}{l}4 \times 10^{-4} \\
7 \times 10^{-5} \\
4 \times 10^{-4}\end{array}$ & {$[28]$} \\
\hline $\begin{array}{l}\mathrm{LaFeO}_{3-\delta} \\
\text { (single crystal) }\end{array}$ & $\begin{array}{l}900 \\
1000\end{array}$ & 7 & $\begin{array}{l}1 \times 10^{-12} \\
5 \times 10^{-12}\end{array}$ & $\begin{array}{l}4 \times 10^{-8} \\
2 \times 10^{-7}\end{array}$ & $\begin{array}{l}3 \times 10^{-5} \\
3 \times 10^{-5}\end{array}$ & {$[38]$} \\
\hline $\mathrm{La}_{0.9} \mathrm{Sr}_{0.1} \mathrm{CoO}_{3-\delta}$ & $\begin{array}{l}900 \\
1000\end{array}$ & 4.5 & $\begin{array}{l}3 \times 10^{-9} \\
2 \times 10^{-8}\end{array}$ & $\begin{array}{l}1 \times 10^{-6} \\
2 \times 10^{-6}\end{array}$ & $\begin{array}{l}2 \times 10^{-3} \\
1 \times 10^{-2}\end{array}$ & {$[29]$} \\
\hline $\mathrm{La}_{0.9} \mathrm{Sr}_{0.1} \mathrm{FeO}_{3-\delta}$ & $\begin{array}{l}900 \\
1000\end{array}$ & 6.5 & $\begin{array}{l}3 \times 10^{-9} \\
1 \times 10^{-8}\end{array}$ & $\begin{array}{l}5 \times 10^{-7} \\
2 \times 10^{-6}\end{array}$ & $\begin{array}{l}6 \times 10^{-3} \\
6 \times 10^{-3}\end{array}$ & [29] \\
\hline $\mathrm{La}_{0.6} \mathrm{Sr}_{0.4} \mathrm{FeO}_{3-\delta}$ & 1000 & 6.5 & $6 \times 10^{-7}$ & $1 \times 10^{-5}$ & $5 \times 10^{-2}$ & [29] \\
\hline
\end{tabular}

a) Calculated from eq. (8).

b) The value can be equated to $j_{\mathrm{ex}}^{0}$, in accordance with eq. (4), by multiplication with a factor 0.045 . Strictly speaking, this holds for $\mathrm{LaCoO}_{3}$.

c) Authors report a two-phase mixture [21]. 
iting overall oxygen transport through the perovskites.

\section{Oxygen permeability of $\mathrm{La}_{0.8} \mathrm{Sr}_{0.2} \mathrm{CoO}_{3-\delta}$ and $\mathrm{SrCo}_{0.8} \mathrm{Fe}_{0.2} \mathrm{O}_{3-\delta}$}

In this section, an analysis is presented of our results from oxygen permeability measurements of the perovskite-type oxides $\mathrm{La}_{0.8} \mathrm{Sr}_{0.2} \mathrm{CoO}_{3-\delta}$ and $\mathrm{SrCo}_{0.8} \mathrm{Fe}_{0.2} \mathrm{O}_{3-\delta}$.

Perovskite oxides were prepared by the thermal decomposition of precursor complexes derived from nitrate solutions using ethylene-diaminetetraacetic acid (EDTA) as a complexing agent. A detailed description of the synthesis route will be presented elsewhere [30].

Permeability data were obtained by exposing opposite sides of sealed disc specimens, having a density above $93 \%$ of theoretical, with an oxygen/nitrogen gas mixture and helium, respectively, using a quartz reactor operating under CSTR conditions. Supramax glass rings (Schott, Nederland B.V.) were used to seal the platinum-ring coated specimen into the reactor. The platinum coating was used to avoid possible chemical interactions between the glass and the specimen. Gas leakage through, for instance, pores or cracks, if present, could be detected gas chromatographically by the presence of nitrogen in the helium stream. The experimental set-up has been described in detail elsewhere $[8,12]$.

In general, perovskites such as $\mathrm{La}_{1-x} \mathrm{Sr}_{x} \mathrm{CoO}_{3-\delta}$ [31-33] and $\mathrm{La}_{1-x} \mathrm{Sr}_{x} \mathrm{FeO}_{3-\delta}$ [34] show a high degree of oxygen nonstoichiometry. The anions are likely to move via a vacancy transport mechanism $[28,29]$. Assuming that all oxygen vacancies are fully ionized and contribute to transport, i.e., no association of oxygen defects, the jump balance yields:

$c_{i} D_{i}=c_{\nu} D_{\nu}$,

where $c_{\nu}=\delta / V_{\mathrm{m}}\left(V_{\mathrm{m}}=\right.$ perovskite molar volume $)$ is the molar concentration and $D_{\nu}$ the diffusion coefficient of oxygen anion vacancies. In first approximation, $D_{\nu}$ may be regarded as constant. Substitution of eqs. (7) and (11) in eq. (1), and integrating across the membrane thickness, $L$, using the relationship $\nabla \mu_{\mathrm{O}_{2}}=\partial R T \ln P_{\mathrm{O}_{2}} / \partial x \quad(x=$ distance coordinate) yields,
$j_{\mathrm{O}_{2}}=-\frac{D_{v}}{4 V_{\mathrm{m}} L} \int_{\ln P_{\mathrm{O}_{2}}}^{\ln P^{\prime \prime} \%_{2}} \delta \mathrm{d} \ln P_{\mathrm{O}_{2}}$,

where the electronic transference number, $t_{\mathrm{cl}}$, has been taken to be unity. The derived equation is slightly modified if the nonstoichiometry becomes high. In accord with classical (hopping) diffusion theories, the diffusion coefficient of oxygen anion vacancies, $D_{v}$ is proportional to $(1-\delta / 3)$, the occupancy of oxygen sites in the perovskite lattice [35]. The oxygen flux can be calculated numerically if experimental data of the nonstoichiometry, $\delta$, as a function of $P_{\mathrm{O}_{2}}$ are available from either gravimetric or coulometric titration measurements. An analytical equation which expresses the oxygen flux as a function of $P_{\mathrm{O}_{2}}$-gradient has been developed by Van Hassel et al. [36], using a simple point defect model to describe the oxygen nonstoichiometry.

Data of nonstoichiometry, $\delta$, for a series of compositions $\mathrm{La}_{1-x} \mathrm{Sr}_{x} \mathrm{CoO}_{3-\delta}$ were obtained by Mizusaki et al. [32] using thermogravimetric measurements in the range $10^{-5} \leq P_{\mathrm{O}_{2}} \leq 1$ atm. The observed $\delta$ values range roughly between 0 and $x / 2$, increasing with temperature, with $\mathrm{Sr}$ content and with decreasing $P_{\mathrm{O}_{2}}$ (figs. 3, 4 and 7 in ref. [32]). At $800^{\circ} \mathrm{C}$, the curves in the $\log \delta-\log P_{\mathrm{O}_{2}}$ plot are almost linear. The slope varies with $\mathrm{Sr}$ content, from $n=-1 / 2$ for $x=0$ to $n=-1 / 16$ for $x=0.7$. Inserting the observed proportionality, $\delta \propto P_{\mathrm{O}_{2}}^{n}$, in eq. (12) one finds, after integration,

$j_{\mathrm{O}_{2}}=\frac{\beta}{L}\left[P_{\mathrm{O}_{2}}^{\prime n}-P_{\mathrm{O}_{2}}^{\prime \prime}\right]$,

where $\beta=D_{\nu} \delta^{0} / 4 n V_{\mathrm{m}}$. The parameter $\delta^{0}$ represents the nonstoichiometry at the reference oxygen pressure $\left(P_{\mathrm{O}_{2}}=1 \mathrm{~atm}\right)$. The limits of integration are the oxygen partial pressures at the gas phase boundaries, whereas single and double primes refer to the high and low pressure side, respectively. Note that for small values of $n$ a logarithmic dependence is obtained by expanding eq. (13) as a power series and truncation after the first term.

The plots in figs. 3 and 4 show that our permeability data obtained for perovskites $\mathrm{La}_{0.8} \mathrm{Sr}_{0.2} \mathrm{CoO}_{3-\delta}$ and $\mathrm{SrCo}_{0.8} \mathrm{Fe}_{0.2} \mathrm{O}_{3-\delta}$ can be fitted well by eq. (13). The fit results for different temperatures and specimen thicknesses are given in table 3. Fitting the data 


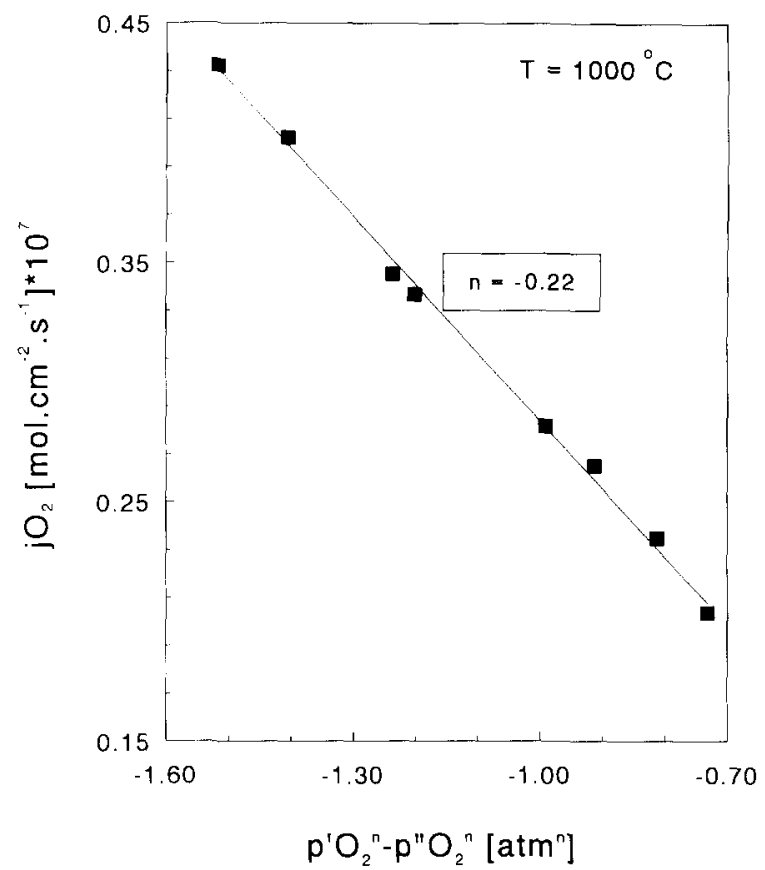

Fig. 3. Pressure dependence of oxygen permeation through $\mathrm{La}_{0.8} \mathrm{Sr}_{0.2} \mathrm{CoO}_{3-\delta}$.

for the composition $\mathrm{La}_{0.8} \mathrm{Sr}_{0.2} \mathrm{CoO}_{3-\delta}$, with the specimen thickness $0.5 \mathrm{~cm}$, yields the same value for the order $n$ at $750^{\circ} \mathrm{C}$ and $1000^{\circ} \mathrm{C} ; n=-0.12$. The latter value is significantly smaller than the one $(n=-0.27$ at $800^{\circ} \mathrm{C}$ ) that can be derived from data of nonstoichiometry reported by Mizusaki et al. (fig. 7 in ref. [32]). It is further noted that $n$ at $1000^{\circ} \mathrm{C}$ increases from -0.22 to -0.12 upon reducing specimen thickness from 0.20 to $0.05 \mathrm{~cm}$, indicating that there are different contributing factors to the value of $n$. Using air on the feed side, the activation energy for the two specimen thicknesses was found to be within the range $120-150 \mathrm{~kJ} / \mathrm{mol}$.

For $\mathrm{SrCo}_{0.8} \mathrm{Fe}_{0.2} \mathrm{O}_{3-\delta}$, the oxygen flux is found proportional to $\left(P_{\mathrm{O}_{2}}^{\prime n}-P_{\mathrm{O}_{2}}^{\prime \prime n}\right)$ with $n=+0.50$ (fig. 4 ). In view of the above theory a conflict arises with data of nonstoichiometry. Coulometric data reported by Nisancioglu and Gür [37] confirm that compounds $\mathrm{SrCo}_{1-x} \mathrm{Fe}_{x} \mathrm{O}_{3-\delta}(x=0.2,0.5,0.8)$ at $850^{\circ} \mathrm{C}$ undergo a significant increase in oxygen vacancy concentration with decreasing oxygen partial pressure relative to the value in air. Regrettably, the authors do not give absolute values of the nonstoichiometry, but if

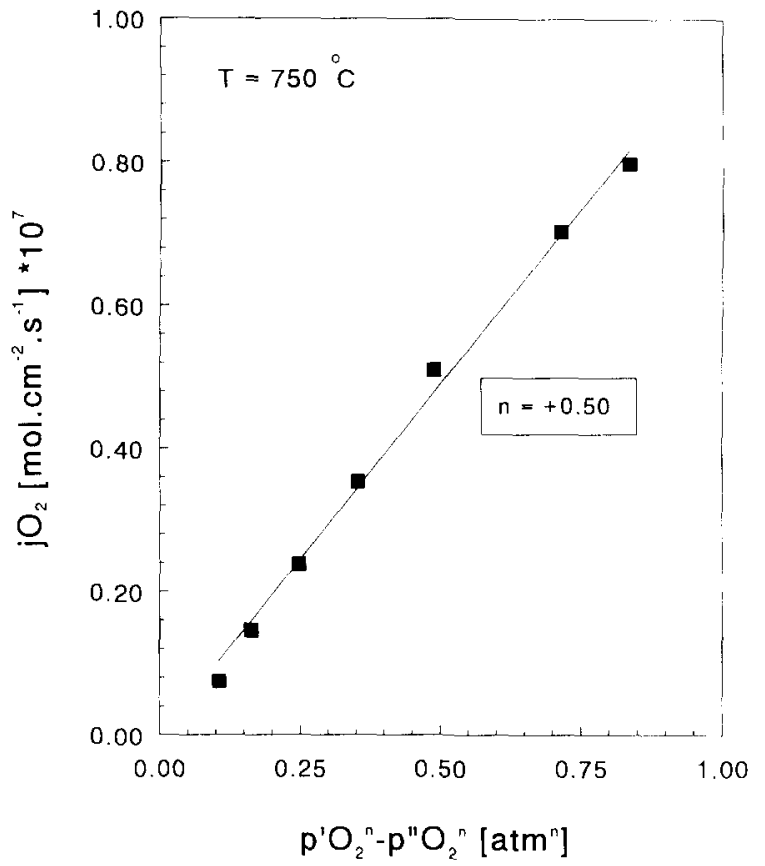

Fig. 4. Pressure dependence of oxygen permeation through $\mathrm{SrCo}_{0.8} \mathrm{Fe}_{0.2} \mathrm{O}_{3-\delta}$.

Table 3

Parameters derived by fitting of oxygen permeability data.

\begin{tabular}{llllr}
\hline Perovskite & $\begin{array}{l}L \\
(\mathrm{~cm})\end{array}$ & $\begin{array}{l}T \\
\left({ }^{\circ} \mathrm{C}\right)\end{array}$ & $\begin{array}{l}\beta \times 10^{10} \\
(\mathrm{~mol} \mathrm{~cm}-1 \\
\left.\mathrm{s}^{-1} \mathrm{~atm}^{-n}\right)\end{array}$ \\
\hline $\mathrm{La}_{0.8} \mathrm{Sr}_{0.2} \mathrm{CoO}_{3-\delta}$ & 0.05 & 750 & $-1.7 \pm 0.1$ & $-0.12 \pm 0.01$ \\
& 0.05 & 1000 & $-105 \pm 2$ & $-0.12 \pm 0.03$ \\
& 0.20 & 1000 & $-57 \pm 6$ & $-0.22 \pm 0.01$ \\
$\mathrm{SrCo}_{0.8} \mathrm{Fe}_{0.2} \mathrm{O}_{3-\delta}$ & 0.20 & 750 & $196 \pm 4$ & $0.50 \pm 0.04$ \\
\hline
\end{tabular}

comparison of their data with that reported for the series of the compositions $\mathrm{La}_{1-x} \mathrm{Sr}_{x} \mathrm{CoO}_{3-\delta}$ by Mizusaki et al. [30] is allowed, a value for $n$ between -0.05 and -0.20 is predicted for the compound $\mathrm{SrCo}_{0.8} \mathrm{Fe}_{0.2} \mathrm{O}_{3-\delta}$.

As is clear, the data obtained from oxygen permeability measurements cannot be treated in terms of the theory presented in this section. An obvious way to reconcile the apparent conflict with a diffusion controlled mechanism is to invoke a surface reaction which exerts a (partial) control over oxygen permeation. In our laboratory a detailed study of the oxygen permeability as a function of membrane thick- 
ness, allowing a more definite answer to the possible involvement of the surface reactions in rate determining oxygen fluxes through perovskites $(\mathrm{La}, \mathrm{Sr})(\mathrm{Co}, \mathrm{Fe}) \mathrm{O}_{3-\delta}$ is in progress.

\section{Conclusions}

A procedure has been described to judge the possible involvement of the surface exchange in limiting the rate of oxygen permeation through mixed-conducting oxides. Examples are provided which show that his procedure, through calculation of $L_{\mathrm{c}}$, representing the characteristic thickness in cases of mixed control, can be used tentatively to distinguish between surface exchange and bulk diffusion controlled rates of oxygen permeation. The $L_{\mathrm{c}}$ values for erbia-stabilized bismuth oxide (BE25) and calciastabilized zirconia (CSZ) are in good agreement with empirical results. The model also explains the data of oxygen permeability of $\mathrm{Bi}_{2} \mathrm{O}_{3}$ substituted with 40 $\mathrm{mol} \%$ of $\mathrm{Tb}$ at the Bi-sites (BT40) which, under the conditions specified in section 5.2, is assumed to be an entirely surface-controlled process. In spite of an enhanced electronic conductivity of BT40, compared with the oxide electrolyte BE25, the oxygen permeabilities are of similar order of magnitude, which is believed to be due to an almost equal activity of both oxides in the surface oxygen exchange reaction.

Regarding their high electronic and ionic conductivities, perovskite-type oxides $(\mathrm{La}, \mathrm{Sr})(\mathrm{Co}, \mathrm{Fe}) \mathrm{O}_{3-\delta}$ are favoured to be used as oxygen separation membranes. As was mentioned earlier [38], chemical and structural instabilities, in particular at low oxygen partial pressure, need to be addressed before exploitation becomes feasible. The limited exchange capability, relative to diffusion, puts limits on the potentialities offered by novel methods for the preparation of thin ceramic films, aiming to improve overall performance or to reduce operating temperatures. Calculations using relevant literature data from ${ }^{18} \mathrm{O}-{ }^{16} \mathrm{O}$ isotopic exchange show that the $L_{\mathrm{c}}$ values, below which the oxygen flux is predominantly controlled by the surface exchange kinetics, roughly range between $20 \mu \mathrm{m}-3000 \mu \mathrm{m}$ (at $900^{\circ} \mathrm{C}$ ), dependent on perovskite composition. First results from oxygen permeability measurements of disk specimens $\mathrm{La}_{0.8} \mathrm{Sr}_{0.2} \mathrm{CoO}_{3-\delta}$ and $\mathrm{SrCo}_{0.8} \mathrm{Fe}_{0.2} \mathrm{O}_{3-\delta}$ obtained by ceramic procedures suggest that the oxygen flux at the conditions covered by experiment, is affected by the surface exchange kinetics. Extended measurements are required to draw more definite conclusions.

\section{References}

[1] A.J. Burggraaf, H.J.M. Bouwmeester, B.A. Boukamp, R.J.R. Uhlhorn and V. Zaspalis, in: Science of Ceramic Interfaces, ed. J. Nowotny (Elseveir, Amsterdam, 1991) pp. 525-568.

[2] E.A. Hazbun, U.S. Patent 4,791,079 (1988).

[3] E.A. Hazbun, U.S. Patent 4,827,071 (1989).

[4] R. DiCosimo, J.D. Burrington and R.K. Grasselli, J. Catal. 102 (1986) 234.

[5] Y. Teraoka, H.M. Zhang, S. Furukawa and N. Yamazoe, Chem. Lett (1985) 1743.

[6] Y. Teraoka, T. Nobunaga and N. Yamazoe, Chem. Lett. (1988) 503.

[7] Y. Teraoka, T. Nobunaga, K. Okamoto, N. Miura and N. Yamazoe, Solid State Ionics 48 (1991) 207.

[8] H. Kruidhof, H.J.M. Bouwmeester, R.H.E. van Doorn and A.J. Burggraaf, Solid State Ionics 63-65 (1993) 816

[9] L. Heyne, in: Solid Electrolytes, Topics in Applied Physics, ed. S. Geller (Springer, Berlin, Heidelberg, New York, 1977) p. 169.

[10] H.L. Tuller, in: Nonstoichiometric Oxides, ed. T. Sørensen (Academic Press, New York, 1981) ch. 6, pp. 271.

[11] S. Dou, C.R. Masson and P.D. Pacey, J. Electrochem. Soc. 132 (1985) 1843.

[12] H.J.M. Bouwmeester, H. Kruidhof, A.J. Burggraaf and P.J. Gellings, Solid State Ionics 53-56 (1992) 460.

[13] B.C.H. Steele, J.A. Kilner, P.F. Dennis, A.E. McHale, M. van Hemert and A.J. Burggraaf, Solid State Ionics 18/19 (1986) 1038.

[14] B.A. Boukamp, I.C. Vinke, K.J. de Vries and A.J. Burggraaf, Solid State Ionics 32/33 (1989) 918.

[15] E.Kh. Kurumchin and M.V. Periliev, Solid State Ionics 42 (1990) 129.

[16] J. Nowotny and J.B. Wagner Jr., Oxid. Met. 15 (1981) 169.

[17] J. Nowotny, Solid State Ionics 28-30 (1988) 1235.

[18] Z. Adamczyck and J. Nowotny, in: Diffusion and Defect Data, Solid State Data-Pt.B, Vols. 15 \& 16, Interface Segregation and Related Properties in Materials, ed. J. Nowotny (1991) p. 285.

[19] B.C.H. Steele, Mater. Sci. Eng. B 13 (1992) 79.

[20] S. Carter, A. Seluk, R.J. Chater, J. Kaida, J.A. Kilner and B.C.H. Steele, Solid State Ionics 53-56 (1992) 597.

[21] Ch. Ftikos, S. Carter and B.C.H. Steele, J. Eur. Ceram. Soc. 12 (1993) 79.

[22] H. Schmalzried, Adv. Ceram. 3 (1981) 254.

[23] P.J. Gellings and H.J.M. Bouwmeester, Catal. Today 12 (1992) 1. 
[24] W.L. Worrell, Solid State Ionics 52 (1992) 147.

[25] I.C. Vinke, B.A. Boukamp, K.J. de Vries and A.J. Burggraaf, Solid State Ionics 57 (1992) 91.

[26] B.A. Boukamp, I.C. Vinke, K.J. de Vries and A.J. Burggraaf, Solid State Ionics 32/33 (1989) 918.

[27] H. Kruidhof and H.J.M. Bouwmeester, unpublished results.

[28] T. Ishigaki, S. Yamauchi, J. Mizusaki, K. Fueki and H. Tamura, J. Solid State Chem. 54 (1984) 100.

[29] T. Ishigaki, S. Yamauchi, K. Kishio, J. Mizusaki and K. Fueki, J. Solid State Chem. 73 (1988) 179

[30] H. Kruidhof, R.H.E. van Doorn, A. Neymeyer and H.J.M. Bouwmeester, to be published.

[31] M. Seppänen, M. Kyto and P. Taskinen, J. Metal. 9 (1980) 3.

[32] J. Mizusaki, Y. Mima, S. Yamauchi, K. Fuki and H. Tagawa, J. Solid State Chem. 80 (1989) 102.
[33] A.N. Petrov, V.A. Cherepanov, O.F. Kononchuk and L.Ya. Gavrilova, J. Solid State Chem. 87 (1990) 69.

[34] J. Mizusaki, M. Yoshihiro, S. Yamauchi and K. Fueki, J. Solid State Chem. 58 (1985) 257.

[35] J.B. Goodenough, Proc. Roy. Soc. (London) A 393 (1984) 215.

[36] B.A. van Hassel, T. Kawada, N. Sakai, H. Yokokawa, M. Dokiya and H.J.M. Bouwmeester, Solid State Ionics 66 (1993) 295.

[37] K. Nisancioglu and T.M. Gür, Proc. 3rd Int. Symp. Solid Oxide Fuel Cells, eds. S.C. Singhal and H. Iwahara, Honolulu, Hawai, 1993, pp. 267.

[38] T. Ishigaki, S. Yamauchi, J. Mizusaki, K. Fueki, H. Naito and T. Adachi, J. Solid State Chem. 55 (1984) 50. 